\title{
Why Open Access to Research and Scholarship?
}

\author{
John Willinsky \\ Department of Language and Literacy Education, University of British Columbia, Vancouver, British Columbia, Canada V6T 1Z4
}

The Internet has changed how we conduct and share research, primarily by increasing the global reach of scholarly communication. With scholarly journals, this possibility of expanding the circulation of knowledge has led to an "open access" movement that is making an increasing number of published, peer-reviewed articles free to read on-line. Authors, editors, publishers, and librarians are exploring new ways of using the Internet to make more of their research available in this way. The Society for Neuroscience provides an excellent example. It has recently increased the level of open access to The Journal of Neuroscience by making back issues, once they are 6 months old, freely accessible to on-line readers. The current president of the Society for Neuroscience, Stephen Heineman, explained that the move to increase access made sense, not only in light of National Institutes of Health and patient advocacy group initiatives, but because "open access is also consistent with the mission of the Society to promote research and to educate the public" (Heineman, 2006), and to that end, the Society is a signatory to the Washington D.C. Principles for Free Access to Science.

Although a movement may be underway to make research more widely available, only a small portion of all the research published each year can be read without either having a subscription or paying to view an individual article. The question that scholarly societies and pub-

Received July 7, 2006; accepted July 7, 2006.

Correspondence should be addressed to John Willinsky at the above address. E-mail: john.willinsky@ubc.ca.

DOI:10.1523/JNEUROSCI.2891-06.2006

Copyright $\odot$ 2006 Society for Neuroscience $\quad 0270-6474 / 06 / 269078-02 \$ 15.00 / 0$ lishers are asking is that even if no one disputes the public good represented by the greater circulation of this knowledge, how can a journal be expected to offer free access to its content and remain financially viable? More than that, why would a scholarly society put subscription revenues at risk to further increase free access to its content?

These difficult questions need to be asked, and innovative approaches need to be explored and tested, because the immediate and long-term benefits of open access are consistent with the very goals of scholarly work. To begin with the simplest of points, made across a growing number of studies, open access leads to a work being cited more often and more quickly (Hitchcock, 2006). That is, work that is made freely accessible makes a greater contribution to research literature. Improved levels of citation, from a society's perspective, also happen to raise the impact factor of a journal. However, the citational advantages of open access represent a limited-term offer that will gradually disappear, of course, as open access becomes more widespread. Thus, it is important to see that something larger and more fundamental is at stake.

The most important reason for pursuing open access comes down to first principles. With its proven ability to increase the circulation of research (meaning that more researchers are turning a critical and appreciative eye to this work), open access strengthens the scientific claims of articles and overall quality of the research literature. Open access to research literature may prove to be the most important scientific gain afforded by the Internet. Nonetheless, open access is as much an epistemological and ethical question, as it is an economic one. It is about journals seeking new ways to increase access to their content, against a backdrop of carefully thought-out plans and definitions for open access (Budapest Open Access Initiative, 2002; Harnad, 2006). Which is only to say that the academic community needs to see these new forms and models of access as part of a broader phenomenon within scholarly publishing and the circulation of knowledge. To that end, allow me to provide a brief tour of open access in action, as this new approach to publishing is currently working itself out in practice.

Open access is the collection of preprints, postprints, and working papers that physicists have been uploading to arXiv.org over the last 14 years. This ensures that their community has free and immediate access to the literature before and after it has been reviewed and published (with that publication duly noted on the paper in arXiv.org). As a result, this literature is read and cited more often for being freely and more immediately available (Kurtz, 2004; E. A. Henneken, M. J. Kurtz, G. Eichhorn, A. Accomazzi, C. Grant, D. Thompson, and S. S. Murray, unpublished observations). Nonetheless, this free access has not had any notable effect on the subscription levels (or the high subscription fees) of the relevant journals (Swain, 2005).

Open access is made up of the e-print archives and institutional repositories that research librarians around the world are setting up for their faculty. In $\sim 5 \mathrm{~min}$, faculty members can upload and index a "preprint" or "postprint" version of their research that is then made freely available on-line in an indexed form with permission from the journal publishers. The vast 
majority of journal publishers, including Elsevier, Springer, and Blackwell, now permit self-archiving in this form, with some restrictions (RoMEo Project, 2006).

Open access is the choice that editors, scholarly societies, and even for-profit publishers (such as BioMed Central, publisher of BMC Neuroscience) have made in creating or converting $>2000$ journals that offer readers complete and immediate open access (Directory of Open Access Journals, 2006). They have found new ways to serve their authors and an expanded number of readers by relying on author fees in some cases, or institutional and society subsidies in others, and on the economics of committed scholarly labor that account for much of the work that has always been done by editors, reviewers, and authors.

Open access has led publishers of medical and agricultural journals to allow free access for scholars in developing countries (including The Journal of Neuroscience), because otherwise the library resources that these scholars have access to are minimal and journal subscriptions scarce. This new approach, however, is having an impact on more than those scholars who would not otherwise have access to the latest discoveries and debates in their field. High school history teachers, for example, are now able to tap into the American Historical Review for new ideas, with indications that for at least some teachers this is a welcome source for their teaching (Bhattacharya, 2003). At the same time, policy analysts in the government are bringing far more research to bear on the policy-making process now that a portion of it is made freely available on-line (Willinsky, 2006).

Open access is taking the form of a number of legislative initiatives, such as the Federal Research Public Access Act of 2006 in the United States, that is intended to ensure that government-funded research is made freely available to the world, while permitting scholarly publishers and societies to continue selling subscriptions by providing a period of embargo on that free access after initial publication. Moreover, whereas some are pressing the National Institutes of Health to move from voluntary to required open access on its funded research, in the United Kingdom, the government's Medical Research Council and Biotechnology and Biological Sciences Research Council have recently mandated open access for all publications resulting from the research that they fund (JULIET, 2006).
Open access is what $80 \%$ of those members of the American public surveyed in a recent Harris Poll (2006) said should be the state of federally funded research, because they can see how such access could be of benefit, for example, to the ill and those who are working to help them, such as those who belong to FORCE (Facing Our Risk of Cancer Empowered), an organization that recently joined the Alliance for Taxpayer Access that lobbies for greater access to research.

Open access has been the topic of the recent editorial in Nature calling for a "more open approach" to the sharing of data on the genetic sequences of the avian flu virus strain, throwing its editorial support behind a letter from two members of the U.S. House of Representatives that calls on the Secretary of Health to ensure open access to scientific data that has been federally funded by having this data placed, as the letter puts it, "in a publicly accessible database, such as GenBank" (Nature, 2006).

Yet, open access is also part of a larger set of worries for the executive directors of scholarly associations. Many of them are witnessing the slow attrition of journal subscriptions among institutions, as libraries face tough choices between the big publishers' bundled titles and the smaller society titles. At the same time, individuals are seeing less value in subscribing to titles that the library delivers to their laptops. How, then, are societies to serve member-authors, whose primary interest is in increasing their readership (rather than seeing it dwindle) and realizing the full benefit of their contributions to the public good? Which way to proceed, then, while ensuring that the journals can be run at the highest professional and scientific levels?

Well, I have tried to suggest that there are many models and approaches to open access, and there may well be others still to come. There is no way to predict which model will prove to be the best means for increasing access to research and scholarship. However, what is perfectly clear is that the Internet is already leading, much as the printing press did centuries ago, to a greater circulation of this work. How much greater that circulation will be, and to whose benefit, are the questions that we should all be asking. The answer will depend, in part, on the leadership and vision of scholarly societies such as this one, as well as the actions of its members (when it comes to self- archiving their published work). At the very least, this is a time to experiment (the very thing we do so well, after all) with new ways and models of scholarly publishing. It is time to see how these new systems can increase the availability of research and scholarship for scholars, professionals, and the public, in ways that will add to the value and quality of this knowledge.

\section{References}

Bhattacharya R (2003) U.S. secondary school outreach effort continues. JSTORnews. Retrieved July 20, 2006, from http://www. jstor.org/news/2003.06/outreach.html/

Budapest Open Access Initiative (BOAI) (2002) Retrieved July 20, 2006, from http://www. soros.org/openaccess/read.shtml/

Directory of Open Access Journals (DOAJ) (2006) University of Lund. Retrieved July 20, 2006, from http://www.doaj.org/

Harnad S (2006) Opening access by overcoming Zeno's paralysis. In: Open access: key strategic, technical and economic aspects, Chap 8 (Jacobs N, ed). Oxford: Chandos. Retrieved July 20, 2006, from http://eprints.ecs. soton.ac.uk/12094/

Harris Poll (2006) Most Americans back online access to federally funded research. Wall Street J Online. Retrieved on July 20, 2006, from http://online.wsj.com/article_email/ SB1 14893698047965609-IMyQjAxMDE2 NDM4MTkzMzE2Wj.html

Heineman S (2006) Open access publishing raises questions. Neuroscience Quarterly. Retrieved July 20, 2006, from http://www. sfn.org/?pagename $=$ neuroscienceQuarterly_ 06winter_main

HitchcockS (2006) The effect of open access and downloads ("hits") on citation impact: a bibliography of studies. The Open Citation Project, University of Southampton. Retrieved July 20, 2006, from http://opcit. eprints.org/oacitation-biblio.html/

JULIET (2006) Research funders' open access policies. University of Nottingham. Retrieved July 20, 2006, from http://www.sherpa. ac.uk/juliet/

Kurtz MJ (2004) Restrictive access policies cut readership of electronic research journal articles by a factor of two. National Policies on Open Access (OA) Provision for University Research Output: an International meeting. Southampton, UK: Southampton University. Retrieved July 20, 2006, from http://opcit. eprints.org/feb19oa/kurtz.pdf/

Nature [no authors listed] (2006) Action stations. Nature 441:1028.

RoMEo Project (2006) Publisher copyright policies and self-archiving. University of Nottingham. Retrieved July 20, 2006, from http://www.sherpa.ac.uk/romeo.php/

Swain A (2005) Immediate self-archiving and its effects on publishers. Retrieved July 20, 2006, from https://arl.org/Lists/SPARC-OAForum/ Message/1581.html/

Willinsky J (2005) The access principle: the case for open access to research and scholarship. Cambridge, MA: MIT. 